\title{
Persistently Reduced Pulmonary Function and Quality of Life in Patients With Mild COVID-19 One Year After Discharge: a Cohort Study
}

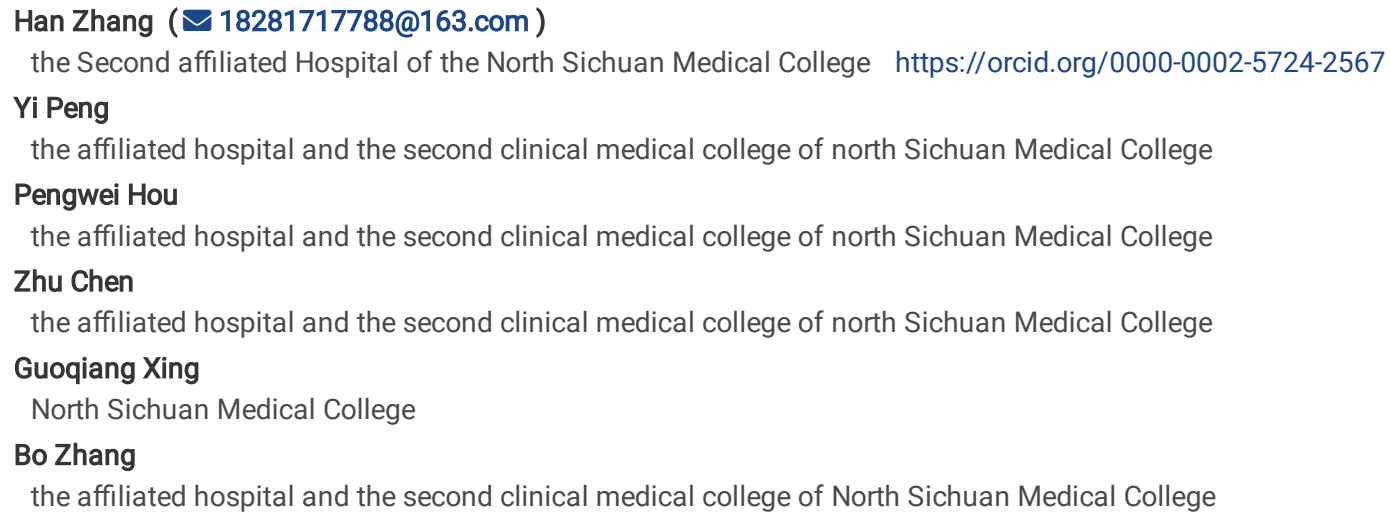




\section{Abstract}

Purpose The epidemiological and clinical features, pathogenesis, and complications of patients with COVID-19 in the acute phase have been well described, but the long-term prognosis and rehabilitation of the patients remain largely unknown.

Methods 39 COVID-19 patients were followed up at 3, 6, and 12 months after discharge. The mental health, pulmonary function, exercise capacity, and quality of life were assessed by Self-Depression Scale and the Self Anxiety Scale, pulmonary function test, 6MWT, 36-Item Short-Form, respectively.

Results Total 33 survivors completed the assessment, $40.8 \pm 0.8$ years, body mass index $=22.7 \pm 1.3 \mathrm{~kg} / \mathrm{m}^{2}$. The length of hospital stays was $19.6 \pm 6.6 \mathrm{~d}$. One year after discharge, the mean scores of SDS and SAS showed decreasing trends from 3-months to 12-months post-discharge. 6 patients (18.2\%) had FVC $<80 \%$ of the predicted value, 12 patients (36.4\%) had FEV1 $<80 \%$ of the predicted value. And $9(27.3 \%), 3(9.1 \%)$, and 2 (6.1\%) of the patients showed reduced FEF25, FEF50, and FEF75 (<70\% expected values), respectively. The mean 6MWD values increased significantly from $397 \pm 25.4 \mathrm{~m}$ at $3-\mathrm{months}$ to $514 \pm 40.8 \mathrm{~m}$ at 12 -months.

Conclusions the impaired pulmonary function in mild COVID-19 survivors was noted after 12 months discharging from hospital. The exercise capacity, mental status, and health status were lower than those of the normal population.

\section{Introduction}

As of May 22, 2021, the COVID-19 Coronavirus Severe Acute Respiratory Syndrome Coronavirus 2 (SARS- CoV-2) pandemic has infected more than 166 million people and caused more than 3.5 million deaths worldwide[1]. COVID-19 patients may be asymptomatic or suffer from mild symptoms of upper respiratory tract infection, to life-threatening sepsis and multiorgan failures with lung injury as one of the most persistent and predominant clinical features[2, 3]. SARS-CoV-2 damages human type II alveolar epithelial cells through cytokine storm and immunopathology-induced pulmonary inflammation and fibrosis[4]. Residual pulmonary fibrosis has been reported in numerous survivors especially the elderly patients of other respiratory viral infectious diseases such as Middle East Respiratory Syndrome (MERS) and Severe Acute Respiratory Syndrome (SARS) $[5,6]$. Organized pneumonitis and fibrosis are also common in later stages of COVID-19[7].

The epidemiological and clinical features, pathogenesis, and complications of patients with COVID-19 in the acute phase have been well described[4], but the long-term prognosis and rehabilitation of the patients remain largely unknown. A few studies have reported persistent symptoms of fatigue, dyspnea[3, 8] [9, 10], and chest imaging abnormalities[7, 11] in patients with severe COVID-19 symptoms 3-and/or-6-months after hospital discharge. Yet no studies have reported on the group with mild COVID-19. The aim of this study was to describe the long-term health status of discharged patients with mild COVID19 and to identify potential risk factors associated with poor outcomes.

\section{Materials And Methods}

Subjects

This is a prospective, longitudinal, follow-up study of patients with mild COVID-19 treated at and discharged from Nanchong Central Hospital from January 2020 to May 2020. A total of 39 eligible patients were enrolled consecutively.

The diagnosis of COVID-19 was based on Centers for Disease Control and Prevention (CDC) criteria. All patients had laboratory confirmation of SARS-CoV2 infection by real-time reverse transcription polymerase chain reaction (RT-PCR) or next-generation sequencing. They all met the uniform discharge criteria (i.e., (i) no fever for 3 consecutive days, (ii) improvement in respiratory symptoms, (iii) significant resolution and recovery of acute lesions on lung imaging, and (iv) two consecutive negative nucleic acid test results for COVID-19- respiratory pathogens) according to the "China COVID-19 Pneumonia Treatment Guidelines" issued by the National Health Commission[12]. And all had been discharged for more than 1 month. Patients with a history of pulmonary resection, neurological disease, or psychiatric disorders were excluded from our study. We obtained written informed consent form the patient, and the study was approved by the Medical Ethics Commission of Nanchong Central Hospital.

We retrospectively analyzed the medical records of these patients, and classified the severity (mild and severe) of the patients according to the following criteria. Patients with severe COVID-19 should meet: 1) tachypnea with Respiratory Rate (RR) $\geq 30$ breaths/min; oxygen saturation $\leq 93 \%$ at rest; 2 ) arterial partial pressure of oxygen /fraction of inspiration oxygen ((PaO2/Fi02) $\leq 300 \mathrm{mmHg} ; 3$ ) chest imaging lesion progression > 50\% within $24-48$ hours; 4 ) respiratory failure requiring mechanical ventilation; 5) the occurrence of shock or combined other organ failure requiring Intensive Care Unit (ICU) monitoring and treatment[12]. COVID-19 patients who did not meet the above criteria are defined as mild case.

Procedure

Outpatients were evaluated at the end of 3,6 and 12 months after discharge. During the follow up visit, subjects underwent the physical examination including pulmonary function test, a standardized 6-min walk test (6MWT) and mental health evaluation. They were instructed to complete the Medical Outcomes Study 36-Item Short-Form General Health Survey (ST-36) to measure Health-Related Quality of Life (HRQoL).

Pulmonary Function Testing 
The pulmonary ventilation function test was performed by a pulmonary function test system (X1, XEEK Medical Equipment Co., Ltd., XiaMen, China) following the procedure instructions of the Pulmonary Function Test. Test parameters include forced expiratory volume in one second (FEV $\mathrm{V}_{1}$ ), Forced vital capacity (FVC), forced vital capacity rate of one second ( $\left.F E V_{1} / F V C\right)$, Forced expiratory flow at $75 \%$ of the pulmonary volume (FEF75\%), forced expiratory flow at $50 \%$ of the pulmonary volume (FEF50\%), and forced expiratory flow at $25 \%$ of the pulmonary volume (FEF25\%). Each test was repeated 3 times with the most standard waveform. $\mathrm{FEV}_{1} / \mathrm{FVC}<70 \%$ was defined as obstructive ventilatory dysfunction, $\mathrm{FVC}<80 \%$ of predicted value indicated restrictive ventilatory dysfunction, and $<70 \%$ of predicted value was defined as impaired FEF $25-75 \%$.

\section{Six Min Walk Test}

The Six-Minute Walk Test (6MWT) is a standardized, objective physical activity test for assessing functional status related to daily activities in patients with cardiopulmonary disease[13]. Walking distance is closely correlated with gender, age and height as reported[14], and we classified the six-minute walking distance (6MWD) by age groups according to the normative reference data collected for 266 healthy adults $>60$ years of age of a 2020 report[15], and the data for 643 healthy subjects between $18-59$ years of age of a 2017 study[16].

36-Item Short-Form General Health Survey questionnaire (SF-36)

The SF-36 consists of eight-items domains that assess physical functioning (PF), social functioning (SF), role limitations due to physical problems (RP), role limitations due to emotional problems (RE), mental health (MH), physical pain (BP), vitality (VT), and general health (GH)[17]. The scores for each domain can range from 0 (worst) to 100 (best), with higher scores indicating better HRQoL. The results of the Chinese version of the SF-36 used in this study were based on a random survey of 1688 Chinese adults older than 18 years of age[18] were compared as the standard reference. The SF-36 domain scores of that survey were divided into three age groups ( 18 to $44 \mathrm{yrs}, 45$ to $64 \mathrm{yrs}$, and $\geq 65 \mathrm{yrs}$ ), which are used to compare with the scores of COVID-19 survivors of different ages.

Mental Health

The Zung Self-Rating Depression Scale (SDS)[19] and The Zung Self-Rating Anxiety Sclae (SAS)[20] were used to screen for depression and anxiety. Both scale consist of 20 items that cover behaviors or symptoms of depression/anxiety disorders with four response choices, ranging from none, or a little of the time, to most, or all of the time. The cut-off values of SDS and SAS are 40 points through a validation study of SDS and SAS for Chinese adults[21]. The higher the score, the higher levels of depression.

\section{Statistical analysis}

Statistical analyses were performed with statistical software (Statistical Package for Social Science, version 22.0; SPSS; Chicago, IL). Comparisons were conducted by independent samples t-test for continuous variables and Mann-Whitney U-test for nonparametric data. Categorical variables were compared with tests. All statistical tests were two-tailed. Statistical significance was considered to be $\mathrm{P}<0.05$. Univariate analysis was used to analyze the potential determinants of 6MWD. Variables that were significant in the univariate analysis $(P<0.1)$ were enrolled in the multivariate analysis. The gender was controlled for in the multivariate model analysis because they were independent determinants of 6MWD.

\section{Results}

Of the enrolled 39 patients with COVID-19 in January 2020, 1 patients (2.5\%) deviated from Nanchong. Among the 38 survivors, 5 patients (10.5\%) were lost to follow-up at the 12-month assessment. Thus, there were only 33 patients (87.2\%), 15 Females (45.5\%), 18 Males (54.5\%), who had completed the three assessments; the mean age of the 33 patients was $40.8 \pm 13.8$ years, body mass index(BMI) was $22.7 \pm 1.3 \mathrm{~kg} / \mathrm{m}^{2}$ ). The hospital length of stay (LOS) for the group was $19.6 \pm 6.6$ day). Three patients were smokers (9.1\%), 6 patients had medical comorbidity (1 chronic obstructive pulmoriary disease (COPD), 1 tuberculosis, 1 Cardiomegaly, 3 hypertension). All patients were diagnosed with mild COVID-19, with fever, cough, fatigue, muscle soreness, and sore throat as the main symptoms.

\section{Pulmonary Function Tests}

The results of pulmonary function tests are shown in Table 1. Generally, lung volume parameters and ventilatory function were well preserved at 3,6 and 12 months. At 3 months, $9 / 33$ (27.2\%) of survivors had a FVC $<80 \%$ of the predicted value, $18 / 33(66.7 \%)$ of survivors had a FEV $1<80 \%$ of the predicted value. the proportion of patients with FEF25, FEF50, FEF75, and MMEF < 70\% values were 51.5\%, 21.2\%, $15.2 \%$, and $39.4 \%$

At 6 months, $7 / 33(21.2 \%)$ of patients had a FVC $<80 \%$ of the predicted value, $16 / 33(48.5 \%)$ of survivors had a FEV $1<80 \%$ of the predicted value. the

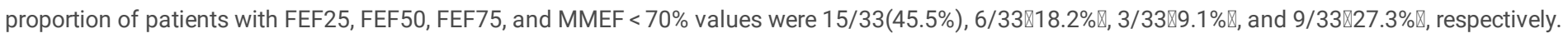

At 12 months, $6 / 33(18.2 \%$ ) of patients had a FVC $<80 \%$ of the predicted value, $36.4 \%$ of patients had a FEV $1<80 \%$ of the predicted value. The proportion of patients with FEF25, FEF50, and FEF75<70\% values were $9 / 33 \otimes 27.3 \% \bigotimes, 3 / 33 \otimes 9.1 \% \bigotimes$, and $2 / 33 \varangle 6.1 \% \rrbracket$, respectively. Thus, there were 23 patients $(23.7 \%)$ with impaired MMEF, whereas $9 \%$ of patients showed a reduction in $\mathrm{FEV}_{1} / \mathrm{FVC}$ at 12 months.

$6 M W D$ 
The mean 6MWD values in COVID-19 survivors increased significantly from $397 \pm 25.4 \mathrm{~m}$ at 3 months to $514 \pm 40.8 \mathrm{~m}$ ) at $12 \mathrm{months}$ (Table 3 ). When subjects were stratified into different age groups, they generally had significantly lower physical capacity than corresponding normal groups of historical normative database. The comparison of the 6MWD of COVID-19 survivors at 3, 6 and 12 months with that of historical normative data is shown in Table 2 .

Univariate and multivariate analyses were performed to investigate the factors associated with 6MWD, with the control for sex (Table 3). The percentage of predicted FVC, FEV 1 , MEF25, and MMEF, and the LOS were positive independent predictors of 6MWD at 3-month post-discharge. The percentages of predicted FVC, $\mathrm{FEV}_{1}$, and MMEF were significant as the positive independent predictors of $6 \mathrm{MWD}$ at 6 months post-discharge. The percentage of predicted $\mathrm{FVC}$ and $\mathrm{FEV}_{1}$ were independent positive predictors of $6 \mathrm{MWD}$ the at 12 months post-discharge.

Mental health

26/33 (78.8\%, F/M: 45.5\%/33.3\%) of Covid-19 survivors had anxiety symptoms at 3 months, 21/33(63.6\%)survivors (Female: $30.3 \%$, Male:33.3\%) at 6 months, and $42.4 \%$ survivors (Female: $21.2 \%$, Male:21.2\%) at 12 months. While, the percentage of subjects with depressive symptoms was $81.8 \%$ (Female:42.4\%, Male: 39.4\%), 66.7\% (Female:36.4\%, Male: 30.3\%), 45.5\% (Female:24.2\%, Male: 21.2\%), respectively. The mean scores of SDS and SAS showed decreasing trends from 3 months to 12 months post-discharge (Table 4).

\section{Health Status of COVID-19 Survivors and Its Correlation with other Factors}

Correlations between pulmonary function parameters, 6MWD, mental health and SF-36 domains at 12 months are shown in Table 5 . There was a significant correlation between FEV $_{1}$ with the two domains of SF-36 (PF and VT) $(r=0.525, p=0.000 ; r=0.483, p=0.018)$, and between FEF25 and VT ( $=$ $0.524, p=0.001)$. 6MWD was significantly correlated with 4 domains $(P F, B P, V T$, and RE) of $S F-36(r=0.492, p=0.013 ; r=0.496, p=0.016 ; r=0.441, p=$ $0.025 ; r=0.43, p=0.032$ ), respectively. Scores of mental health status (SDS and SAS) were negatively correlated with all SF-36 domains except PF and RP $(r=-0.082, p=0.651 ; r=-0.215, p=0.225 ; r=-0.347, p=0.054 ; r=-0.12, p=0.949)$, respectively.

A comparison of SF-36 domain scores of the patients at 3, 6 and 12 months after discharge with normative data is shown in Table 6. The health status of COVID-19 survivors was still significantly impaired at 3, 6 and 12 months post-discharge compared to that of the normal control population of the same age groups.

\section{Discussion}

This cohort study assessed the long-term health status and prognosis of discharge patients with mild COVID-19. Residual abnormalities in lung function, exercise capacity, health status, and anxiety and depression were still persistent in these patients 12 months after discharge. These results are consistent with the recent report of 1,733 COVID-19 survivors that muscle weakness, sleep difficulties, anxiety and depression were common in COVID-19 survivors[10] 6-month after discharge.

COVID-19 can cause excessive inflammatory responses in deep airway and alveolar that damages the lungs' and immune system's structure and function[22]. Assessment of pulmonary function in this study showed that $51.5 \%$ of the COVID- 19 survivors had FEF $25<70 \%$ at 3 months while $27.3 \%$ of the survivors had FEF $25<70 \%$ at 12 months of discharge, indicating long-term dysfunction of small airway after COVID-19 infection. Small airways are fine bronchi with an internal diameter of $2 \mathrm{~mm}$ or less in the inspiratory state, which are prone to pathological changes such as airway narrowing or obstruction due to inflammation[23]. In a 2-week follow-up study of 137 discharged COVID-19 patients[22], Lv et al found that $57.3 \%$ of non-severe COVID-19 survivors had MEF25 < 70\%, restrictive ventilation disorder and small airway obstruction. Our results of persistent abnormality in FEF25, FEF50, FEF75, MMEF and small airway function in discharged patients with mild COVID-19 are in agreement with the report of different degrees of pneumonia and lung lesions in discharged Covid-19 patients[24].

The 6-minute walk test (6MWT) is a test of exercise capacity for people at different health conditions. Although 6MWD was improved considerably in COVID-19 patients over the 12 months period, it remains significantly impaired in COVID-19 patients compared to that of age- and gender-matched normal controls. After controlling for age and gender, the percentages of predicted FVC, FEV 1 , FEF25, and MMEF, and the LOS were positive independent predictor of $6 \mathrm{MWD}$ at 3 months, the percentages of predicted $\mathrm{FVC}, \mathrm{FEV}_{1}$, and MMEF had a greater effect on $6 \mathrm{MWD}$ at 6 months, while the percentages of predicted FVC and predicted $\mathrm{FEV}_{1}$ were the positive independent predictors of $6 \mathrm{MWD}$ at 12 months.

A recent study has shown that COVID-19 survivors self-reported fatigue and muscle weakness after 6 months of discharge from hospital[10]. A previous long-term follow-up study of severe acute respiratory syndrome (SARS) survivors showed significantly reduced exercise capacity of SARS survivors compared to healthy controls[25]. Systemic steroid therapy, in-hospital acquired disease, and in-time management of lung injury during ICU stay are considered important factors for improving 6MWD in acute respiratory distress syndrome (ARDS) survivors[26]. Patients in our study only had mild COVID19 and without steroid therapy and ICU admission. We also find that the length of hospital stay and lung function of the patients were independent predictors of the reduced 6MWD at 3 months post-discharge. Most of our patients rested on bed during the average 19 days of hospitalization due to dyspnea and environmental immobilization. Given that the relatively well preserved pulmonary function in majority of mild COVID-19 survivors, the poor performance on 6MWT in our patients may also be due to myopathy, decreased physical activity and potential cardiac diastolic dysfunction[2, 13]. However, as the lung dysfunction of the survivors is the only factor related to the 6MWD 12 months after discharge, this suggests that lung function is the key limiting factor underlying the extend of physical rehabilitation. This is corroborated by the findings of Ong et al's study on exercise capacity recovery in SARS survivors[27]. 
COVID-19 survivors were still depressed and anxious 12 months after the discharge. The anxiety and depression were particularly pronounced in two subjects from rural areas. It may be partly due to the effect of COVID-19 perse and partly due to the hostile environment and rejection from surrounding people who were fearful being infected by the lethal COVID-19 disease. A previous follow-up study showed similar finding[10]. Other factors including the direct impacts of viral infection, immune overresponse or exhaustion/suppression, hypercorticosteroids, hospitalization/isolation, etc. may all have attributed to this[28]. It should be noted that public panic and fear of the rampant high transmission and high mortality rate of COVID-19 and the lockdown of the country at the beginning of the COVID-19 pandemic may have contributed to the rejection, psychological and emotional disturbances of COVID-19 patients.

In addition, the young adult of COVID-19 survivors (18-44 years) show significant impairment in the physical problems (RP), physical pain (BP), social functioning (SF) domains of HRQoL and the old adults of COVID-19 survivors (45-64 years) showed significant decrease in SF at 12 months after discharge. Whereas pulmonary functions (FEV 1 and FEF25) were positively correlated with PF, VT of SF-36, and 6MWD positively correlated with PF, BP, VT, RE domains in SF-36, depression or anxiety were negatively correlated with BP, GH, VT, SF, RE, and MH domains of SF-36. These results further support the close cross link between pulmonary function, physical and mental health and quality of life. To our knowledge, to date there are no reports of HRQoL in COVID-19 survivors at 1 year after discharge, although association between impaired HRQoL and abnormal pulmonary function have been reported in SARS survivors 1 year after recovery[25, 26].

\section{Limitations}

There are limitations for this study. The sample size of the study was small for definite conclusions. Only patients with mild COVID-19 were enrolled in this study, limiting the application of the findings to other COVID-19 survivors, especially patients with severe COVID-19. The respiratory muscle testing was not performed because patients' complaints of generalized muscle weakness at the initial follow-up. Others reported that SARS survivors had respiratory muscle weakness at 12 months[25]. The proportion of patients in the current study reporting previous chronic lung disease and cardiovascular disease was low, so we did not measure the effect of non-pulmonary factors (e.g., muscle dysfunction, steroid- or virus-induced myopathy, cardiac disorders, or severe polymyalgia) on impairment of lung function and exercise capacity in patients.

\section{Conclusions}

In summary, significant impairment in ventilation of the small airways and in exercise capacity are persistently found in patients with mild COVID-19 one year after discharge. The risk of psychological complications including anxiety or depression remains an important issue in these patients. These findings support the need for continued post-discharge care for those patients and patients with severe COVID-19. So far, the long-term rehabilitation strategy for COVID-19 survivors remains to be developed. Our results suggest the need of focus on the improvement of small airway ventilation, exercise capacity and emotional support for for mild COVID-19 survivors.

\section{Declarations}

\section{Funding}

this study was funded by the Technology Research and Development Projects Foundation of Nanchong (No. 20YFZJ0120).

\section{Conflicts of Interest}

The authors have no conflicts of interest to declare.

\section{References}

1. World Health Organization. COVID-19 dashboard.2019. Accessed May 22, 2021. https://covid19.who.int/.

2. Bohm, M., et al., Coronavirus Disease 2019 (COVID-19) and its implications for cardiovascular care: expert document from the German Cardiac Society and the World Heart Federation. Clin Res Cardiol, 2020. 109(12): p. 1446-1459.

3. Wang, F., R.M. Kream, and G.B. Stefano, Long-Term Respiratory and Neurological Sequelae of COVID-19. Med Sci Monit, 2020. 26: p. e928996.

4. Wiersinga, W.J., et al., Pathophysiology, Transmission, Diagnosis, and Treatment of Coronavirus Disease 2019 (COVID-19): A Review. JAMA, 2020. 324(8): p. 782-793.

5. Li XY, S.B., Wang CT, et al., A follow-up study on acute respiratory distress syndrome survivors after extracorporeal membrane oxygenation by pulmonary high-resolution CT. Arch Iran Med, 2015. 18: p. 6-11.

6. Venkataraman T, F.M., The role of epidermal growth factor receptor (EGFR) signaling in SARS coronavirus-induced pulmonary fibrosis. Antiviral Res, 2017. 143: p. 142-50.

7. Ye Z, Z.Y., Wang Y, et al., Chest CT manifestations of new coronavirus disease 2019 (COVID-19): a pictorial review. Eur Radiol, 2020. 30: p. $4381-9$.

8. Zhao, Y.M., et al., Follow-up study of the pulmonary function and related physiological characteristics of COVID-19 survivors three months after recovery. EClinicalMedicine, 2020. 25: p. 100463.

9. Liang, L., et al., Three-month Follow-up Study of Survivors of Coronavirus Disease 2019 after Discharge. J Korean Med Sci, 2020. 35(47): p. e418.

10. Huang, C., et al., 6-month consequences of COVID-19 in patients discharged from hospital: a cohort study. The Lancet, 2021. 397(10270): p. $220-232$. 
11. Sabina A. Guler, L.E., Catherine Aubry-Beigelman,Pierre-Olivier Bridevaux, Martin Brutsche, Christian Clarenbach ,Christian Garzoni, Thomas K. Geiser, Alexandra Lenoir ,Marco Mancinetti, Bruno Naccini, Sebastian R. Ott, Lise Piquilloud,Maura Prella, Yok-Ai Que, Paula M. Soccal, Christophe von Garnier,Manuela Funke-Chambour, Pulmonary function and radiological features 4 months after COVID-19 first results from the national prospective observational swiss COVID-19 lung study. Eur Respir J, 2021. 57.

12. Lin L, L.T., Interpretation of "Guidelines for the Diagnosis and Treatment of Novel Coronavirus (2019-nCoV) Infection by the National Health Commission (Trial Version 5)". Zhonghua Yi Xue Za Zhi, 2020. 100: p. 805-7.

13. Pitta F, T.T., Spruit MA, Probst VS, Decramer M, Gosselink R., Characteristics of physical activities in daily life in chronic obstructive pulmonary disease. Am J Respir Crit Care Med. , 2005. 171(9): p. 972-7.

14. Halliday, S.J., et al., Six-minute walk distance in healthy young adults. Respir Med, 2020. 165: p. 105933.

15. Zou, H., et al., Six-minute walking distance in healthy Chinese people older than 60 years. BMC Pulm Med, 2020. 20(1): p. 177.

16. Zou, H., et al., Reference equations for the six-minute walk distance in the healthy Chinese population aged 18-59 years. PLoS One, 2017. 12(9): p. e0184669.

17. Ware JE, S.K., Kosinski M, et al., SF-36 Health survey- manual and interpretation guide. Boston, MA: The Health Institute, New England Medical Center, 1993.

18. L Li, H.M.W., Y Shen, Chinese SF-36 Health Survey- translation, cultural adaptation, validation, and normalisation. J Epidemiol Community Health, 2003. 57: p. 259-263.

19. WWK., Z., A self-rating depression scale. Arch Gen Psychiatry., 1965. 12(1): p. 63-70.

20. WWK., Z., A rating instrument for anxiety disorders. Psychosomatics., 1971. 12: p. 371-79.

21. Li, D.Q.Q.S., Differential validity of SAS and SDS among psychiatric non-psychotic outpatients and their partners. Chin Mental Health J, 2012. 26(9): p. 676-79.

22. Lv, D., et al., Pulmonary function of patients with 2019 novel coronavirus induced-pneumonia: a retrospective cohort study. Ann Palliat Med, 2020. 9(5): p. 3447-3452.

23. Stewart JI, C.G., The small airways in chronic obstructive pulmonary disease: pathology and effects on disease progression and survival. . Curr Opin Pulm Med, 2013. 19: p. 109-115.

24. Zou Wenbin, L.C., Cai Yixin, Zeng Zhilin, Zhang Ni, Fu Xiangning, Comparison of Recovery Phase CT Features between Mild/ moderate and Severe/ critical Coronavirus Disease 2019 Patients. Acta Acad Med Sin, 2020. 42(3): p. 370-75.

25. Hui, D.S., et al., Impact of severe acute respiratory syndrome (SARS) on pulmonary function, functional capacity and quality of life in a cohort of survivors. Thorax, 2005. 60(5): p. 401-9.

26. Herridge MS, C.A., Tansey CM, et al., One-year outcomes in survivors of the acute respiratory distress syndrome. N Engl J Med 2003. 348: p. 683-93.

27. Ong, K.C., et al., Pulmonary function and exercise capacity in survivors of severe acute respiratory syndrome. Eur Respir J, 2004. 24(3): p. 436-42.

28. Rogers JP, C.E., Oliver D, et al. , Psychiatric and neuropsychiatric presentations associated with severe coronavirus infections: a systematic review and meta-analysis with comparison to the COVID-19 pandemic. Lancet Psychiatry 2020. 7: p. 611-27.

\section{Tables}

Table 1

Pulmonary function tests of COVID-19 survivors $(n=33)$ at 3, 6 and 12 months post-discharge

\begin{tabular}{|llllll|}
\hline parameters & $\begin{array}{l}\text { at 3- month } \\
\text { (mean, SD) }\end{array}$ & $\begin{array}{l}\text { at 6- month } \\
\text { (mean, SD) }\end{array}$ & $\begin{array}{l}\text { at 12-month } \\
\text { (mean, SD) }\end{array}$ & $\begin{array}{l}\text { t/p-value } \\
\text { 3-month vs. 12-month }\end{array}$ & $\begin{array}{l}\text { t/p-value } \\
\text { 6-month vs. 12-month }\end{array}$ \\
\hline FVC, \% of predicted & $80.0(4.3)$ & $84.9(6.8)$ & $87.2(7.4)$ & $5.27 / 0.000^{* *}$ & $2.819 / 0.008^{* *}$ \\
\hline FEV,$\%$ of predicted & $67.2(4.3)$ & $71.4(5.8)$ & $73.9(7.3)$ & $4.567 / 0.000 * *$ & $1.913 / 0.065$ \\
\hline FEV 1 FVC\% & $76.8(5.9)$ & $85.3(6.2)$ & $86.2(5.3)$ & $5.213 / 0.000^{* *}$ & $1.643 / 0.089$ \\
\hline FEF25, \% of predicted & $68.3(5.6)$ & $69.0(6.0)$ & $74.5(7.0)$ & $4.931 / 0.000^{* *}$ & $4.818 / 0.000^{* *}$ \\
\hline FEF50, \% of predicted & $72.6(5.8)$ & $74.3(5.0)$ & $77.8(5.4)$ & $3.583 / 0.001^{* *}$ & $2.962 / 0.006 * *$ \\
\hline FEF75, \% of predicted & $77.5(4.4)$ & $78.4(4.4)$ & $79.9(4.8)$ & $2.739 / 0.01^{* *}$ & $1.765 / 0.087$ \\
\hline MMEF, \% of predicted & $69.5(5.7)$ & $71.7(6.1)$ & $74.8(5.9)$ & $6.214 / 0.000 * *$ & $4.462 / 0.000^{* *}$ \\
\hline
\end{tabular}

** significant at $\mathrm{p}<0.01$. 
Table 2

Mean values of 6MWD of COVID-19 Survivors $(n=33)$ at 3, 6 and 12 months compared with Normative Data

\begin{tabular}{|lllll|}
\hline Variables & $\begin{array}{l}\text { Normal } \\
\text { Mean (SD) }\end{array}$ & $\begin{array}{l}\text { at 3-month } \\
\text { Mean, (SD) }\end{array}$ & $\begin{array}{l}\text { at 6- month } \\
\text { Mean, (SD) }\end{array}$ & $\begin{array}{l}\text { at 12-month } \\
\text { Mean (SD) }\end{array}$ \\
\hline Females $(\mathrm{n}=15)$ & $578(49.85)$ & $387.2(75.5) * *$ & $402.3(30.4) * *$ & $536.7(40.6) * *$ \\
\hline Males $(\mathrm{n}=18)$ & $623(52.3)$ & $396(57.9) * *$ & $405.7(28.4) * *$ & $495.3(30.8) * *$ \\
\hline
\end{tabular}

** significant at $p<0.01$. 
Table 3

Predictors of 6MWD at 6 and 12 months From Symptom Onset $(n=33)$

\begin{tabular}{|c|c|c|c|c|c|c|c|c|c|c|c|c|}
\hline & 3 months & & & & 6 months & & & & 12 months & & & \\
\hline Predictors & $\begin{array}{l}\text { Univariate } \\
\text { Analysis }\end{array}$ & SE & $\begin{array}{l}\text { Multivariate } \\
\text { Analysis } \\
\text { (Adjusted } \\
\mathrm{R}^{2}=0.553 \text { ) }\end{array}$ & SE & $\begin{array}{l}\text { Univariate } \\
\text { Analysis }\end{array}$ & SE & $\begin{array}{l}\text { Multivariate } \\
\text { Analysis } \\
\text { (Adjusted } \\
\mathrm{R}^{2}=0.921 \text { ) }\end{array}$ & SE & $\begin{array}{l}\text { Univariate } \\
\text { Analysis }\end{array}$ & SE & $\begin{array}{l}\text { Multivariate } \\
\text { Analysis } \\
\text { (Adjusted } \\
\mathrm{R}^{2}=0.805 \text { ) }\end{array}$ & SE \\
\hline $\mathrm{BMI}$ & & 3.21 & & & & 3.694 & & & & 4.89 & & 2.668 \\
\hline $\begin{array}{l}\beta \\
\text { coefficient }\end{array}$ & -0.332 & & & & -0.28 & & & & -0.435 & & -0.082 & \\
\hline $\mathrm{p}$ Value & 0.068 & & & & 0.114 & & & & 0.011 & & 0.362 & \\
\hline LOS & & 0.573 & & 0.572 & & 0.675 & & 0.339 & & 0.817 & & 0.655 \\
\hline $\begin{array}{l}\beta \\
\text { coefficient }\end{array}$ & -0.53 & & -0.293 & & -0.507 & & -0.079 & & -0.573 & & -0.089 & \\
\hline $\mathrm{p}$ Value & 0.001 & & 0.046 & & 0.002 & & 0.314 & & 0.000 & & 0.403 & \\
\hline $\begin{array}{l}\mathrm{FVC}, \% \text { of } \\
\text { predicted }\end{array}$ & & 1.012 & & 0.867 & & 0.723 & & 0.677 & & 0.49 & & 0.674 \\
\hline $\begin{array}{l}\beta \\
\text { coefficient }\end{array}$ & 0.875 & & 0.79 & & 0.676 & & 0.05 & & 0.87 & & 0.629 & \\
\hline $\mathrm{p}$ Value & 0.021 & & 0.006 & & 0.001 & & 0.036 & & 0.040 & & 0.023 & \\
\hline $\begin{array}{l}\mathrm{FEV}_{1}, \% \text { of } \\
\text { predicted }\end{array}$ & & 0.944 & & 0.725 & & 0.553 & & 0.519 & & 0.497 & & 0.505 \\
\hline $\begin{array}{l}\beta \\
\text { coefficient }\end{array}$ & 0.448 & & 0.343 & & 0.723 & & 0.211 & & 0.293 & & 0.289 & \\
\hline $\mathrm{p}$ Value & 0.008 & & 0.023 & & 0.000 & & 0.017 & & 0.003 & & 0.004 & \\
\hline $\begin{array}{l}\text { FEF25, \% } \\
\text { of } \\
\text { predicted }\end{array}$ & & 0.856 & & 0.896 & & 0.732 & & 0.613 & & 0.57 & & \\
\hline $\begin{array}{l}\beta \\
\text { coefficient }\end{array}$ & 0.632 & & 0.308 & & 0.336 & & 0.181 & & 0.075 & & & \\
\hline $\mathrm{p}$ Value & 0.002 & & 0.047 & & 0.036 & & 0.167 & & 0.45 & & & \\
\hline $\begin{array}{l}\text { FEF50, \% } \\
\text { of } \\
\text { predicted }\end{array}$ & & 0.862 & & & & 0.718 & & & & 0.653 & & \\
\hline $\begin{array}{l}\beta \\
\text { coefficient }\end{array}$ & -0.008 & & & & 0.064 & & & & -0.023 & & & \\
\hline $\mathrm{p}$ Value & 0.967 & & & & 0.612 & & & & 0.792 & & & \\
\hline $\begin{array}{l}\text { FEF75, \% } \\
\text { of } \\
\text { predicted }\end{array}$ & & 1.225 & & & & 0.793 & & & & 1.072 & & \\
\hline $\begin{array}{l}\beta \\
\text { coefficient }\end{array}$ & -0.109 & & & & -0.162 & & & & -0.071 & & & \\
\hline $\mathrm{p}$ Value & 0.608 & & & & 0.194 & & & & 0.576 & & & \\
\hline $\begin{array}{l}\text { MMEF, \% } \\
\text { of } \\
\text { predicted }\end{array}$ & & 0.814 & & 0.761 & & 0.481 & & 0.445 & & 0.879 & & \\
\hline $\begin{array}{l}\beta \\
\text { coefficient }\end{array}$ & 0.425 & & 0.327 & & 0.561 & & 0.558 & & 0.118 & & & \\
\hline $\mathrm{p}$ Value & 0.029 & & 0.007 & & 0.000 & & 0.000 & & 0.361 & & & \\
\hline
\end{tabular}


Table 4

Mental health of COVID-19 survivors $(n=33)$ at 3-, 6 - and 12-months post-discharge

\begin{tabular}{|cllll|}
\hline \multirow{2}{*}{ SDS } & & $\begin{array}{l}\text { 3-months } \\
\text { Mean(SD) }\end{array}$ & $\begin{array}{l}\text { 6-months } \\
\text { Mean(SD) }\end{array}$ & $\begin{array}{l}\text { 12-months } \\
\text { Mean(SD) }\end{array}$ \\
\cline { 2 - 6 } & Male $(n=18)$ & $45.4(8.6)$ & $45.6(9.3)$ & $36.6(7.9)$ \\
\hline \multirow{2}{*}{ SAS } & Female( $n=15)$ & $48.4(9.5)$ & $45.8(11.6)$ & $39.3(9.5)$ \\
\cline { 2 - 6 } & Male $(n=18)$ & $46.3(12.3)$ & $44.9(10.2)$ & $38.7(11.3)$ \\
\hline
\end{tabular}

Table 5

Correlations among HRQoL, Lung function, 6 MWD, and Mental Health at 12 Months $(n=33)$

\begin{tabular}{|lllllllll|}
\hline & PF & RP & BP & GH & VT & SF & RE & MH \\
\hline FVC & 0.194 & 0.091 & 0.124 & 0.036 & 0.036 & 0.197 & 0.035 & 0.049 \\
\hline FEV 1 & $0.525^{\star *}$ & 0.180 & 0.178 & 0.214 & $0.483^{*}$ & 0.137 & 0.049 & 0.132 \\
\hline FEF25 & 0.119 & 0.216 & 0.128 & 0.175 & $0.524^{\star *}$ & 0.239 & 0.074 & 0.024 \\
\hline FEF50 & 0.082 & 0.005 & 0.138 & 0.097 & 0.113 & 0.22 & 0.104 & 0.128 \\
\hline FEF75 & 0.108 & 0.058 & 0.106 & 0.235 & 0.062 & 0.031 & 0.166 & 0.165 \\
\hline MMEF & 0.154 & 0.198 & 0.07 & 0.229 & 0.145 & 0.245 & 0.238 & 0.086 \\
\hline 6MWD & $0.492^{*}$ & 0.016 & $0.496^{*}$ & 0.13 & $0.441^{*}$ & 0.103 & $0.43^{*}$ & 0.079 \\
\hline SDS & -0.082 & -0.215 & $-0.518^{* *}$ & $-0.358^{*}$ & $-0.413^{*}$ & $-0.411^{*}$ & $-0.355^{*}$ & $-0.509^{* *}$ \\
\hline SAS & -0.347 & -0.12 & $-0.495^{*}$ & $-0.579^{* *}$ & $-0.412^{*}$ & $-0.645^{* *}$ & $-0.500^{* *}$ & $-0.459^{*}$ \\
\hline
\end{tabular}

* significant at $p<0.05$.

** significant at $p<0.01$. 
Table 6

Changes in SF-36 scores at 3, 6,12 Months post-discharge and compared with the normative date of the general population of different age groups

\begin{tabular}{|c|c|c|c|c|}
\hline SF-36 Domains/Age Groups & $\begin{array}{l}\text { Normal, } \\
\text { Mean(SD) }\end{array}$ & $\begin{array}{l}\text { 3- months vs Normal, } \\
\text { Mean (SD) }\end{array}$ & $\begin{array}{l}\text { 6-months vs Normal, } \\
\text { Mean (SD) }\end{array}$ & 12 months vs Normal, Mean (SD) \\
\hline \multicolumn{5}{|l|}{ PF } \\
\hline $18-44$ & $86.0(18.0)$ & $73.7(9.6) * *$ & $75.8(10.2)$ * & $83.4(10.1)$ \\
\hline $45-64$ & $82.0(17.4)$ & $68.4(6.5)$ & $72.9(7.5)$ & $77.5(8.4)$ \\
\hline$\geqq 65$ & $68.5(24.5)$ & $34.5(8.3)$ * & $34.0(7.1)$ * & $52.5(10.6)$ \\
\hline \multicolumn{5}{|l|}{$\mathrm{RP}$} \\
\hline $18-44$ & $85.3(29.0)$ & $54.6(12.4) * *$ & $58.7(15.2) * *$ & $71.6(16.2)$ * \\
\hline $45-64$ & $80.4(34.3)$ & $52.7(15.3)$ ** & $52.5(18.5) * *$ & $72.9(10.1)$ \\
\hline$\geqq 65$ & $68.3(42.8)$ & $45.7(8.4)$ & $47.5(10.6)$ & $50.0(7.1)$ \\
\hline \multicolumn{5}{|l|}{$\mathrm{BP}$} \\
\hline $18-44$ & $85.0(17.8)$ & $64.5(7.9)$ ** & $66.8(8.3)$ ** & $70.8(10.7)$ ** \\
\hline $45-64$ & $78.4(21.8)$ & $71.2(9.6)$ & $70.4(8.6)$ & $68.3(10.1)$ \\
\hline$\geqq 65$ & $75.3(23.6)$ & $72.5(8.3)$ & $70.0(7.1)$ & $60.0(14.1)$ \\
\hline \multicolumn{5}{|l|}{$\mathrm{GH}$} \\
\hline $18-44$ & $60.0(19.8)$ & $62.4(7.5)$ & $63.7(9.3)$ & $65.2(14.3)$ \\
\hline $45-64$ & $54.0(19.4)$ & $54.1(6.7)$ & $57.3(8.7)$ & $63.3(18.6)$ \\
\hline$\geqq 65$ & $50.3(20.9)$ & $46.6(11.2)$ & $48.5(4.9)$ & $36.0(29.7)$ \\
\hline \multicolumn{5}{|l|}{ VT } \\
\hline $18-44$ & 53.3(20.3) & $53.2(13.4)$ & $55.3(16.8)$ & $59.2(21.6)$ \\
\hline $45-64$ & $51.2(21.1)$ & $36.7(6.3)$ * & $38.5(5.9)$ * & 47.1(14.7) \\
\hline$\geqq 65$ & $48.4(22.1)$ & $34.6(23.4)$ & $35.0(28.3)$ & $40.0(35.4)$ \\
\hline \multicolumn{5}{|l|}{ SF } \\
\hline $18-44$ & $84.2(16.9)$ & $64.5(18.4)$ ** & $66.7(20.7)$ ** & $76.0(19.1)$ * \\
\hline $45-64$ & $82.8(17.6)$ & $51.2(17.5)$ ** & $55.8(18.3)$ ** & $68.0(21.7)$ ** \\
\hline$\geqq 65$ & 79.3(20.9) & $55.6(23.5)$ & $57.0(26.9)$ & $62.3(35.0)$ \\
\hline \multicolumn{5}{|l|}{$\mathrm{RE}$} \\
\hline $18-44$ & $85.3(30.5)$ & $72.3(10.5)$ & $74.0(13.9)$ & $77.9(11.8)$ \\
\hline $45-64$ & $85.1(32.2)$ & 69.6(10.4) & $71.4(12.2)$ & $74.8(15.2)$ \\
\hline$\geqq 65$ & $79.5(38.8)$ & $65.8(14.5)$ & $67.5(17.7)$ & $65.5(0.7)$ \\
\hline \multicolumn{5}{|l|}{$\mathrm{MH}$} \\
\hline $18-44$ & $57.9(21.4)$ & $52.4(3.6)$ & $54.2(3.9)$ & $57.8(8.1)$ \\
\hline $45-64$ & $61.3(23.5)$ & $40.8(13.7)$ & $41.6(14.4) * \star$ & $57.2(10.1)$ \\
\hline$\geqq 65$ & $62.4(25.1)$ & $41.4(20.4)$ & $40.0(21.5)$ & $50.0(25.5)$ \\
\hline
\end{tabular}

Of the normal group: 832 subjects were in the age groups 18 to 44 years, 356 subjects were in the age groups 45 to 64 years, 128 subjects were in the age groups more than $\geqq 65$.

* significant at $p<0.05$.

** significant at $p<0.01$. 